\title{
Glasgow's Race Anti-Realism: Experimental Philosophy and Thought Experiments
}

\section{(pre-publication draft: please do not cite without permission)}

Joshua Glasgow argues that there are no races, using experimental philosophy and a more traditional thought-experiment approach. ${ }^{1}$ A closer look, however, finds these anti-realist arguments much less convincing. Glasgow's overall argumentative strategy is to endorse a relatively thin conception of what the concept of race requires, only to argue that even that thin notion is tied up too much with problematic elements that do not exist in any of the candidategroups that we might call races. This paper argues that a social-kind view of race can handle the objections Glasgow presents without much in the way of unwelcome implications, and some of his positive arguments turn out to be much more favorable to a social-kind view than Glasgow allows.

Section 1 looks at Glasgow's overall strategy, beginning with some experimental philosophy that he concludes shows that the ordinary concept of race is a thin concept of race but a biological concept. Section 2 then evaluates the implications of the experimental philosophy work Glasgow points to, concluding that Glasgow improperly takes this data to show that the ordinary concept of race requires thinking of races as natural kinds. Section 3 challengess Glasgow's argument that we should stop believing in races because belief in races involves too many false beliefs about the groups we are calling races. Section 4 looks at some thought experiments Glasgow uses to bolster his other arguments, suggesting that various counterfactual scenarios provide counterexamples for the claim that the socially-constructed groups we call races are genuine races. I argue that these thought experiments need not lead to his conclusion. Section 5 looks at a quick argument Glasgow gives in his summary, to the effect that our criteria 
for race-membership are inconsistent, arguing that it, too, is unmotivated. His arguments, therefore, do not give strong enough reasons to be anti-realists about race.

\section{The Thin Concept of Race and Some Experimental Data}

This section presents an overview of Glasgow's position and arguments. He accepts a thinner account of the concept of race than some anti-realists, allowing himself to face a harder target, since it is much easier to find that nothing in the world actually fits a broader concept of race, but it is more difficult to argue that nothing fits a thinner concept. If he can show the latter, he has made a stronger case. To motivate the use of the thinner concept, he presents some data from experimental philosophy aimed at finding out what concept of race ordinary people are working from. He concludes that the ordinary concept of race is biological, which is a key premise in his primary anti-realist argument.

Glasgow sets out his position in terms of Michael Hardimon's distinction between thick and thin analyses of the concept of race. ${ }^{2} \mathrm{~A}$ thin conception might be something like:

(H1) a group of human beings

(H2) distinguished by certain observable physical traits

(H3) originally coming from a specific geographical region

Hardimon defends the existence of races given a thin conception. Surely there are groups of human beings distinguishable by observable physical traits with ancestry traceable to specific geographical regions, and such groups match up fairly closely with the actual groups often 
described with racially-associated terms. Even those who question whether there is a black race would accept that there is at least a vague-boundaried group of people called black or AfricanAmerican in the United States, that this group of people has observable physical traits distinctive of the group and common among its members, making most of its members readily identifiable by appearance, and that they by and large have a significant amount of ancestry traceable to subSaharan Africa. This is so even if there might be people not usually classified in that group who have significant ancestry from the same regions of Africa, and it is so even if there might be people in that group whose ancestry comes more from other places than those parts of the African continent. This is not to say that such groups would be discoverable by natural science and therefore count as natural kinds, even on a relatively thin notion of what counts as a natural kind. Much has been written against that sort of prospect. ${ }^{3}$

It might be helpful to consider natural kinds in terms of Ian Hacking's three sticking points about social construction vs. natural kinds: contingency, nominalism, and stability. ${ }^{4}$ If races are social constructions, then the contingency issue is whether a different social course, including choices made by society that could have been made differently, could have led to very different notions of what races are, which races there are, and who is a member of which races, and there is little hope that simply doing natural science well would inevitably lead to the exact notion of race that we in fact have and the very groups we call races with the boundary conditions for membership that they actually have. And this is not true just because a different social history would lead to different reproductive patterns and thus different people would result because the very nature of how we think of these categories would be different. The nominalism issue is whether the structure of our categories cannot be found to rise out of nature itself but has to be brought to it by our own conceptual apparatus, which results not just from innate ideas but 
from how our thinking has been conditioned by those contingent social choices just mentioned. Stability is whether the categories and concepts of race will tend to remain the same or change as continued social changes occur.

We can easily identify groups that have observable phenotypic characteristics that we associate with being race-related traits, groups whose ancestry and ancestral geographical location is largely common. We can do that even if the reasons these groups have been singled out, with the boundary lines they have, are determined enough by social criteria that could have gone differently, are not grounded in structure identifiable by purely natural-science methods, and will likely be susceptible further change resulting from social changes in the future. That would mean that there could be clear candidates for reference for racial terms along Hardimon's lines, and the path to rejecting races cannot rely on the lack of any such candidate groups. It still remains open whether our race-terms do in fact refer to such groups (a linguistic question) and whether such groups are genuine races (a metaphysical question). But questions about those matters do not mean that there are no existing candidate-groups about which we can even ask such questions, and the existence of such candidate-groups need not be tied to the notion that such phenotypic groups serving as candidate-races are natural kinds in the sense most philosophers have in mind.

Glasgow points out that we might find our way to denying the existence of races by adding various elements to Hardimon's thin concept: ${ }^{5}$

(a) Robust Genetic Kind: races have some genetic commonality distinctive to each race

(b) Biobehavioral: containing biological differences leading to differences in culture, moral traits, behavior, and other non-outward traits

(c) Purist: containing some element of racial purity

(d) Sociobiological: populations with reproductive isolation result in distinctive cultures 
A thicker concept of race involving some, or all, of these four elements allows an easier argument against the existence of races. If this is the correct concept of race, and nothing exists that fits this concept, then there are no races. If we could establish that the thinner concept of race is the ordinary concept of race, then it would be easier to find existing groups for our raceterms to refer to. If a thicker concept is at work, it is much harder to find something that can fit as a reference group for any racial term.

Aren't there such thickening elements in race-thinking? Hardimon distinguishes how we happen to think about race (our conception of race) from what is essential to race-thinking (the concept of race). If the thicker elements are part of the very concept of race, then something would not be a race without them. If the thicker elements are just part of our conception of race, then something could still fit the concept of race even if it did not fit our particular conception of race. We would have false views about race, but falsity would not necessarily require rejecting the term 'race' the way it would if the very concept of race required the thicker elements. If that is right, then the argument that races are not real requires arguing that these more robust elements are part of the concept of race itself and not just aspects of some conceptions of race.

Glasgow sets this all out and then admits he has strong sympathy for a thin concept of race. ${ }^{6}$ He does give an argument against a biological version of a thin account of race (which he calls the "superficial theory"7 of race), drawing attention to arbitrariness in the kinds of factors involved in a thin notion of race. ${ }^{8}$ This would be problematic if one's account of race takes the thin notion of race to correspond to some non-arbitrary biological reality. Someone holding to a thin account that takes races to be socially-constructed, on the other hand, does not face that problem. Arbitrariness might suggest something non-natural, and thus arbitrariness in the factors underlying what one takes to be natural kinds is a problem, but biological arbitrariness is what 
we should expect among the factors that determine social kinds. And social-kind theorists will point out that these groups are not socially arbitrary but are grounded in social facts. Glasgow's sympathy for a thin concept of race, then, cannot be ruled out entirely just because the biological version of it faces problems. Nevertheless, his sympathy amounts to acknowledging his intuitions, intuitions someone else might not share.

So how do we sort out what the ordinary concept of race is, other than just expressing differences between our intuitions? After all, someone might take their intuitions about their conception of race to be intuitions about the very concept of race. Glasgow argues that we are best off doing experimental philosophy, seeing what the ordinary concept of race is by doing research to see how the concept of race actually works. He does use some armchair theorizing in his argument against the existence of races, but part of his argument relies on empirical data.

Some empirical data comes from asking people about their views of race ${ }^{9}$. This should help elucidate what Sally Haslanger calls the manifest concept ${ }^{10}$ of race, which is what people think about race. The operative concept, on the other hand, has to do with people's engagement in various practices that involve racial categorization. If people classify each other in ways that do not line up with how they reflect on their classifications, then the manifest and operative concepts come apart. Empirical data from experimental philosophy studying people's selfdescriptions of their attitudes about race might illuminate their manifest concept of race. Empirical data from experimental studies of how people interact racially, without asking them to reflect on such interactions, might show what the operative concept involves. There are limits to the methods we can use to discover what sort of concept people have about race. We have to do the best we can, but we should keep the limits of this sort of investigation in mind as we proceed. 
Glasgow considers several attempts to examine people's judgments on difficult cases of racial classification. In 1996 Lawrence A. Hirschfeld published his work along these lines. ${ }^{11} \mathrm{He}$ showed people color drawings of a black person and a white person and asked what race their child would be (with the picture of the child obscured so as to show no skin color). They were given the opportunity to answer as they chose. For example, six wrote, "mulatto" but four of those six misspelled it. ${ }^{12}$ Glasgow describes the result: "adults, at a rate significantly greater than chance, said that the child of one black and one white parent, as depicted in those pictures, would be black." ${ }^{13}$ Hirschfeld represents it graphically, not numerically but it looks to me asif it is about 66\% saying "black," single digits saying "white," and 38\% saying what Hirschfeld classifies as "something else."

To be clear, this is going by the parents' pictures. It isn't really judging an actual person's race. It is making a prediction about what a resulting child might be like and then concluding what the child's race will be. People might give completely different answers if they saw the children's pictures, with some pictures showing someone looking like what they consider a fairly typically black person would look and other pictures looking much more like what they would expect a white person to look like. If the skin color of the person whose race is being assigned affects how likely the person is to count as black, mixed, or white, then this test would reveal nothing about an actual practice.

Glasgow and his colleagues devised a different test. ${ }^{14}$ There are legal cases of people who look white, think of themselves as white, and are thought of as white by other people, but they discover that they are legally black because of a few distant ancestors. The one-drop rule would classify such a person as black. That settles it for some people, but Glasgow and his co-authors 
wanted to see if ordinary people's judgments fit with such a result. They presented the test subjects with the following case:

Susie is a middle-aged woman. She "looks white" to the average person on the street. She was raised to believe she was white. Her co-workers and friends all think of her as white. Now, in her mid-40s, she discovers that she has a couple of black ancestors, such that her great-great-great grandparents consist of only two black people and 30 white people ${ }^{15}$.

Participants could choose if Susie is white, black, mixed, sometimes white and sometimes black, or none of the above. Only 2.2 percent of the 449 U.S. adults in the study considered her black.

Glasgow concluded in 2009 that the one-drop rule was no longer even part of the ordinary conception of race, never mind the very concept of race, even if Hirschfeld's study shows us that a significant number of adults in 1996 thought very-near black ancestry might be enough to outweigh white ancestry. So the argument that the one-drop rule is part of the very concept of race, and therefore nothing can meet the criteria required to be a race, seems to be strongly at odds with the actual concept of race that at least many adults in the U.S. seem to have.

Consider another claim some use to distinguish the concept of race from any existing purported race groups. The claim is that race-thinking is essentialist, assuming some kind of racial essence possessed by all members of a race, where that essence is not some massivelydisjunctive property but is supposed to be more robustly natural. Some substantial set of properties is supposed to be true of all members of a race by virtue of their being members of that race, and such features cannot be removed.

One experiment Glasgow and his co-authors conducted somewhat undermines claims that the ordinary concept of race is like that. They presented a case like one originally proposed by 
Charles Mills. ${ }^{16}$ George is black, but he manages to change his appearance through scientific alteration of his skin tone. Over half of respondents considered him no longer to be black. Surely they haven't thought through the case very far. Consider what George's children would look like or what scientists would conclude when comparing his pigmentation DNA with his actual skin color. Even so, this strongly suggests that ancestry is not a required part of the concept of race, if people can even entertain the idea that someone born black can cease to be black by such an operation.

Glasgow cites several sources that seem to indicate biological features as determinative of many people's judgments about racial classification. ${ }^{17}$ In several cases, the biological traits are merely visible appearance. Glasgow points out that such traits are grounded in genetics (or at least “commonly understood to result from genetics"). ${ }^{18}$ One study ${ }^{19}$ points to geographical origins of one's ancestors as a determinant of racial classification in some people's minds, but Glasgow points out that visible traits were "core parts of the definition of race" for some participants, and some explicitly ruled out geographic origins. Two studies ${ }^{20}$ Glasgow points to looked at people's judgments about black people and white people that seem to indicate naturalkind judgments. The "categories are thought to be discrete, natural, immutable, historically stable, and to have necessary features." 21

At the end of this we see some empirical support for Glasgow's claim that the ordinary concept of race is thin but biological. In the next section, I will offer several concerns I have with Glasgow's use of this evidence.

2. Implications of the Experimental Philosophy Data 
What should we conclude from such studies? Glasgow takes biological features involved with people's judgments on race-membership to mean that races, if they exist, must be biological categories. This section will argue that such a conclusion does not follow. Consider first the last set of studies from the previous section. As Glasgow says, "four of the five items - immutability, discreteness, stability, and containing necessary features - could also be true of social categories." ${ }^{22}$ Yet he insists that the fifth, naturalness, seems to indicate a biological category, because its contrasting option was artificiality. The exact wording is "Some categories are more natural than others, whereas others are more artificial". ${ }^{23}$

So does that mean the ordinary concept of race entails that races are natural kinds? I do not think so. The participants in the study might just be taking the physical characteristics themselves to be natural, as we would expect most people to do. That would then place these studies in the same category as the others Glasgow cites that deal just with visible traits rather than moving up to the more theoretical level of natural vs. artificial categories. Does thinking races are grounded in such physical, visible traits mean races are natural kinds?

It is easy to imagine an ordinary person considering racial categories being determined by physical appearance, being asked whether those categories are natural or artificial, and concluding that they are natural on the ground that those visible traits are determined by nature rather than nurture. This ordinary person's thinking about race does not deal with what philosophers call natural kinds or what theoreticians mean by artificiality in the sense of social kinds or social constructions. They probably just recognize that skin color is not determined by social classification, nutritional differences, education, and so on. That's a far cry from having a 
concept of race that takes races to be natural kinds in the philosopher's sense. So I do not see how these studies go very far toward showing the ordinary concept of race to involve a biological kind of the relevant sort.

Furthermore, Glasgow notes that some of these studies point to other factors that can defeat the presumption of an appearance-based category, such as (a) the phenomenon of passing as white, where someone with the appearance of being white will, upon closer examination, turn out to be black or (b) the insistence of some that multiple factors influence racial classification, with visible traits only occupying part of that process, and the history of discrimination playing some role as well. Consider the complex set of factors raised in the 2007 U.S. presidential primaries, when some people claimed that Barack Obama is not really black because he did not have American-slave ancestors and did not grow up in a community with the cultural values of American blacks. ${ }^{24} \mathrm{He}$ self-identified as black, and the media came to refer to him as black, presumably because of his self-identification and the fact that he looks like people ordinarily taken to be black. People who look like him face discrimination or unconscious bias whenever black people would experience it. Perhaps the desire to tell the story of the first black president played some role in their choice of terms as well. Some, however, seemed to need the peer pressure of everyone else calling him black to be able to do it themselves.

There are several ways to handle this case. One might compare being black in the U.S. with being Italian. Italian Americans are one ethnic minority among whites in the U.S. ${ }^{25}$ The factors leading people to hesitate about then-Senator Obama's blackness might have to do with ethnic blackness, an ethnic sub-category of the overall black race. Statements about whether someone is "really black" do not always indicate whether they mean something racial or something merely cultural or ethnic (where ethnicity is not taken to be racial). But the very fact 
that a significant response to the claim pointed to how he would be treated means that in many people's minds social factors will determine whether someone gets classified as black, and how others classify you does seem more racial than ethnic.

Glasgow points out that such judgments might be different among different racial groups. ${ }^{26}$ Whites are more likely to reject a one-drop rule than blacks, and self-identified African Americans are more likely to point to social factors like being discriminated against. These complexities are important for constructing a positive view about how racial classification works. We should recognize the complexity as showing that biological traits are not the entire process, even if we ignore my above point that we can explain the biological traits as part of our classificational procedure without taking those doing the classifying to have in mind something like natural kinds. Even apart from that point, we would not have races as pure natural kinds. We would just have races that are determined in part by naturally-occurring characteristics.

What about Glasgow's case of someone using a machine to change racial appearance? ${ }^{27}$ Just over half of the participants in the study took George's change not to indicate a genuine race-change. That means just under half were not so sure. We should not ignore that, but it does mean that many see it as much harder to change one's race than to change one's appearance. That does seem to indicate an element more fundamental than skin color. But do we know exactly what element that is? It may just be a sense that one's past racial classification cannot be so easily changed, without the commitment that there is some deep racial essence that causes one's race independently of visible traits. The visible traits might be still doing the work, but one's past visible traits matter. One cannot erase past traits with such a machine.

Furthermore, consider Anatole, ${ }^{28}$ a standard passing-as-white case: 
Anatole was raised as a member of the Black race and most of his ancestors are Black, but in early adulthood he started presenting himself as White. He cut off all relationships with the Black community, he steeped himself in White culture, and he was accepted as White by the White community. After Anatole successfully presented himself as White, was he:
a. White
b. Black
c. Mixed
d. Sometimes White and Sometimes Black
e. None of the above. ${ }^{29}$

Anatole was taken by 23 percent of respondents, mostly Americans, to have become white upon adopting white culture and self-identification. That is not a large percentage, but it is an awful lot if the very concept of race is supposed to be a biological concept. Purely social factors differ between (1) Anatole after thinking of himself as white and (2) Anatole when he previously lived among blacks and thought of himself as black.

Alternatively, there is a modal property: being possibly identified as black when one's children's appearance is discovered. Then the current appearance is not all that indicative. That does not require believing in a natural kind. It might just mean that one's visible traits and the genetic features that affect appearance both count toward influencing what category one belongs to. Such a view is compatible with thinking races are determined by nothing but visible traits, provided you include modal properties related to visible appearance, although other factors might also be taken into account such as potential discrimination, and some individual respondents even took social factors to be the sole determinant, such as the 23 percent who took the example of Anatole to have become white rather than to have been just passing. So it is hard for me to see such studies as very conclusive, even if they had given a result higher than $51 \%$ taking there to be something more than current appearance. 
Furthermore, a social-kind view need not take race to be a purely social phenomenon. Consider Alain Locke's notion that races are defined entirely socially and do not rely on any of the criteria involved in biological races but instead on cultural phenomena. ${ }^{30}$ He goes as far as saying, "if you have the same manners and customs and have allegiance to the same social system, you belong to the same race [or social kind,] even though ethnically you may not." ${ }^{\text {" For }}$ Locke, races are civilizations or cultures. He allows for a biological concept of race, but there are no such races corresponding to that concept, and the social kind he envisions races fitting into does not involve any biological elements.

We might take races to be groups whose existence or significance depends on social factors but whose identifying characteristics are biological, e.g. phenotypical characteristics and/or ancestry. The biological traits would not distinguish these particular groups as races in some scientifically non-arbitrary way. Social practices do that job. But the social practices might single out these groups rather than others because of distinctive biological characteristics whose use to determine racial boundary lines is biologically arbitrary but socially explicable. What Ron Mallon calls a folk objectivist account, which he attributes to Charles Mills, has exactly this feature:

And it is true that a folk objectivist account would allow that people are ascribed to races on the basis of features, at least some of which are biological and heritable. However, this, by itself, stops far short of suggesting that these biological and heritable traits form an interesting kind from the point of view of biology, and a fortiriori, it stops short of racialism. Instead, a folk objectivist ought to hold that the heritable traits the form a basis of racial ascription are part of what I call a 'thin racial endowment'. ${ }^{32}$

We end up with social categories constituted by social practices that pick out visible physical traits such as those identified in all the studies Glasgow cites. I would prefer to take the biological features as Mills does, to be among the factors that form the socially-determined 
criteria for belonging to races, as we find also in accounts from Jorge Gracia ${ }^{33}$ and, less explicitly, in Paul Taylor's social-constructionism, ${ }^{34}$ which makes ready reference to "social conditions [that] assign meaning to appearance and ancestry" as part of what makes races what they are. Lucius Outlaw's socio-natural kind view ${ }^{35}$ is similar, and Linda Alcoff sees at least some racial-classification systems as like this. ${ }^{36}$

However, even social-constructionists who resist such an account, as Bernard Boxill ${ }^{37}$ and Ronald Sundstrom ${ }^{38}$ do, might perhaps accept that biological characteristics are reliableenough indicators of race. To think they could not be, on the ground that races are socially constructed, is to confuse metaphysics with epistemology. Either way, it is possible to deny that races are natural kinds or biological categories while holding that we can identify someone's race by biological traits, perhaps even that the social processes that determine racial-categorization factors include facts like skin color, hair type, and so on. If races, then, are that kind of social category, then the fact that people connect racial groups with biological traits does not necessarily indicate that the concept of race is of what philosophers call a natural kind.

The studies show nothing about race being a biological category, since such social categories would equally explain the data. All the data establish is that races are determined using criteria that are biological, not that the categories' existence or significance must be explained purely by biology for there to be races. The data do not show that races would have to be natural kinds, even non-essentialist natural kinds (i.e. highly-disjunctive properties that are natural only in the sense that they are useful in the natural sciences). The more useful for natural science that such a grouping might be, the less likely the group will correspond to the groupings a sociologist might mean when using racial classifications or the groupings an ordinary person would put people into when asked which people are black, which are white, which are Asian, 
and so $\mathrm{on}^{39}$. It does not seem as if the groupings that are most significant in daily life and in sociological study are the same groupings that would be useful for natural science, even if both groups exist. ${ }^{40}$ The groups that people think they are referring to when they use race-language are not the biological groups that such biological-race theorists have recently defended ${ }^{41}$.

\section{The role of false beliefs}

Even if experimental philosophy can show that the ordinary concept of race as involving biological features is compatible with races being social kinds, as the previous section argues, Glasgow has a further argument. The common belief in biological races makes it a mistake to call such groups races. This section argues that, even if many people believe racial groups to be natural kinds or biological categories, we have no reason to take that to mean there are no races, even if there are no biological races.

Glasgow argues that the actual belief that races are biological categories would be strong enough to make the category of race an empty category. The groups we call races are not races:

Constructivists are surely right that our race-based practices (including not least our racetalk) have influenced us and sorted us into social groups. But why should we say that those groups are races? Appiah got us to think about this question in terms of witchcraft: in using the language of 'witch', we didn't sort ourselves into witches and non-witches, because our witch-talk was predicated on a conceptually non-negotiable but factually false belief, namely that there were people who cavorted with the devil. Similarly, our race-talk is predicated on a conceptually non-negotiable but factually false belief, namely that we fall into biological races. This contrasts with decisively social kinds, like professional kinds. When we talk about being a journalist or a teacher, there is no false belief (negotiable or not) that the biological world contains these kinds. So, on this anticonstructivist position, our racial identifications might produce sociohistorical facts and 
even social collectivities of some sort, but, as a conceptual matter, those social collectivities do not constitute races. ${ }^{42}$

So the analogy with social kinds like journalists or teachers fails. There are no false beliefs at the bottom of our concept of journalists or teachers, whereas there are with races. Glasgow thus thinks races are more analogous to witches, defined as "those who cavort with the devil". 43

One set of models for comparison comes from the sciences. We once thought heat was a substance called caloric. According to an earlier theory, phlogiston was a substance explaining heat and combustion. It turned out neither exists. There is no such thing as a substance that underlies the phenomenon of heat or combustion. Oxygen underlies combustion in one respect, but it behaves in the opposite way of what these theories proposed. Both phlogiston and caloric were rejected. We have reached a consensus about caloric and phlogiston: we ought to be eliminativists about such proposed substances.

Nonetheless, we did not reject heat. Heat was thought to be the substance caloric, and it was supposed to move around from one object to another, heating them up when it entered into them and cooling them off when it left them. Apparently some even proposed frigoric, a substance explaining cold. We have now rejected such substances while not rejecting the notion of heat. How could this have happened? Wasn't it part of the concept of heat that it be a substance?

Perhaps it was just a part of the ordinary conception of heat that it be a substance, whereas the concept could be continued without thinking of it as a substance. The fact that we did not abandon the concept of heat suggests as much. When we read works of literature from before the transition, during a time when people thought of heat as a substance, should we take 
those works to be engaging in reference-failure the way we do when we read historical references to caloric or phlogiston (when the author believes in such things)? If so, they think they are referring to something, but there was nothing that they might be referring to. The world would have had to have been different for their terms to latch on to anything.

But that seems not to be the case with heat. We developed a reductionist account of heat. We did not stop believing that there is such a thing. We just changed how we thought about it. Heat is not a substance. Our language about heat really refers to kinetic energy, and our measurement of temperature identifies the average kinetic energy of the particles of anything whose temperature we are measuring. We can continue to talk about heat, and we do not seem to think that people talking about heat four-hundred years ago were referring to something else. They just had mistaken beliefs about what it is that they were referring to.

Are races more like caloric and phlogiston, then, or are they more like heat? One test is how easily we can maintain the same concept while changing the conception. The difficulty with administering such a test with race now is that we are still in the transition period. Children learn in school that heat is about motion of particles rather than a substance. We are not quite at a point where the biological information about the categories we call races is as well known. Without prophetic abilities or some special access to what will continue to happen as this process goes on, we cannot make much of a reasoned judgment about whether the concept of race will weather the transition as more people become informed about the scientific facts.

Another helpful case is atoms. The early atomists, Leucippus and Democritus, took atoms to be indivisible chunks of matter that obviously had some size in space, even odd shapes so that they could latch on to each other when they made contact ${ }^{44}$. The Epicureans were still working 
with this model of the atom when they revived it in the Hellenistic period ${ }^{45}$. The corpuscularian early moderns who rejuvenated atomism allowed for some change in the inner characteristics of the atoms ${ }^{46}$. When John Dalton solidified the modern notion of the atom as composed of a nucleus, lots of empty space, and electrons orbiting the nucleus, we had come a long way from the notion of an indivisible particle that seemed so central to the ancient notion of atoms. Meanwhile, a number of early modern atomists still took atoms to be indivisible ${ }^{47}$.

Did we then discover that they were wrong but that atoms existed anyway? Or did they just retain the language inappropriately, because the very concept of an atom was something that was uninstantiated in the real world? We should probably see the notion of indivisibility as no longer central to the concept of an atom (even if it was central for the ancient Greeks), but some people's conception of atoms included it, while the corpuscularians' conception of atoms did not. So two competing conceptions of atoms were at work during the early modern period, and one of them turned out to be closer to John Dalton's eventual model of the atom that we settled on.

Are races more like atoms in the early modern period, where competing conceptions allow for a diversity of views about what races are, all of which are views about races, or does the concept itself preclude such discussions? I would suggest that the very possibility of debate on the subject should lead us to lean toward the former, and the experimental philosophy above showing people's responses to questions about racial classification shows a kind of fluidity in the concept of race, allowing for a number of different conceptions that different people might apply in different contexts. We do not see a radical change with race as from ancient Greek atoms in physics today, which involved a change in both sense and reference, but the early modern period illustrates the compatibility of competing conceptions of atoms with a more general concept of an atom, which is what I am suggesting is going on with race today. 
Here is another test, one that can operate while false beliefs about the nature of something are still present in the general population. Consider false beliefs about Halloween and Thanksgiving. Many Americans have false views about the origins of Thanksgiving. They think it is a holiday begun by the Pilgrims in the Massachusetts colony when the colonists and the native peoples celebrated the first harvest since founding the colony. There was a tradition of harvest festivals among the colonists, and the native peoples did have some involvement in it, but it was not until Abraham Lincoln's presidency that a holiday called Thanksgiving was established on Thursdays toward the end of each November, and the stories of the "first Thanksgiving" only then were applied to this new holiday. The Pilgrims' practices did not establish the holiday, and there were even colonial celebrations of harvests and giving thanks before 1621 in Virginia. Will an ordinary person, upon being corrected about when and how Thanksgiving was established, suddenly conclude that they now believe in a different holiday from the one everyone else believes in or even abandon belief in the holiday's existence altogether? Plenty of people do understand this information, and none of them stop believing in the holiday or think they celebrate a different holiday from the one that most people celebrate.

Most Americans think of Halloween as a secular holiday, but there are minority contingents who emphasize either Christian or pagan origins. The actual history is complex, but there was a festival that early Christians in the British Isles replaced with their All Hallows Eve practices, in much the same way that Christmas replaced Saturnalia for early Roman Christians. There are Christians who refuse to practice Halloween, considering it a pagan holiday involving occult practices in secular dress. In a sense, they see trick-or-treaters as cooperating with Satan, albeit unwittingly. Most people, including most Christians, would think of trick-or-treating as (at the very least) a relatively innocent practice. But do they think they are referring to different 
things when they talk about Halloween? Its reference is determined by its outward practices and by chronological measurements (namely the evening of Oct 31 every year), not by the competing views about the nature of those activities. People can have different conceptions about the very nature of what the holiday is while still referring to the same entity with the word 'Halloween'. They can even have debates about the nature of Halloween while never even considering that they might be talking about different holidays, only one of them actually existing.

In $19^{\text {th }}$ century American slavery, many took those they called Negroes to be something like what Aristotle described as natural slaves. Many today believe that nothing fits Aristotle's category of a natural slave, someone who is incapable of living life except under the direction of someone else or at least best off under the determination of others who seek the person's best interest. Such statements, in trying to correct for errors of the past, fail to account for those with serious developmental disabilities or debilitating mental conditions, who really do need someone else's supervision and care in order to thrive. Aristotelian slaves are not an empty category, but $19^{\text {th }}$ century slave-justifiers falsely believed that everyone they called Negroes were natural slaves in the Aristotelian sense. One might try to argue that their conception of what it is to be a Negro had something like this as a defining trait. Yet there were debates at the time about whether such claims were true, and those engaging in such debates did not think they were referring to different groups when engaging in such debates. They presented their arguments as debates about what is true about that group of people, not about whether the group exists or whether it is the same group the other side is referring to.

I should say that it strikes me as a little strange to class Glasgow with eliminativists or fictionalists, and I do not mean this for the reason he would distinguish himself from them. He insists that we should reconstruct something like races without the false beliefs, and once that is 
done we would then have social groups that we could call races*. That is indeed a difference between his view and the views that leave us not believing in races or thinking races are fictions (whether worth retaining or not). But is Glasgow's view the kind of error theory about race that most error theorists about race hold? Glasgow does not claim that the groups we call races are non-existent. His claim is that they exist but are not races. So the difference between his view and a social constructionist view is not about what social realities exist. The only difference is about whether we speak truly if we apply the word 'race' to those social entities that society does call races.

This dispute reminds me of Augustine's criticism of the Stoic view of passions or emotions. ${ }^{48}$ He observes that the Stoics recognized a category of mental states that they called good feelings ${ }^{49}$. They insisted that such states are not emotions. They thus do allow for some kinds of feelings that are perfectly fine, without modifying their view that emotions are always bad. To be an emotion, the inner state has to be out of the control of careful reasoning. An impulse is an emotion only if it prevents careful reasoning. Augustine resists this definition and insists on seeing these good feelings as emotions. The Stoics stubbornly refuse to call them emotions, even though most everyone else does. They have their carefully-defined category of emotions. Augustine prefers to go with the general populace's use of emotion-terms to refer to these things that the Stoics insist on calling good feelings.

Glasgow is not doing exactly what the Stoics do here. He does have arguments that the general understanding of races does not fit with the general practice of calling these groups races, but most people do not see it, because they have false beliefs about these groups. Augustine does not accuse the Stoics of that. He just thinks they misuse language because of a poor definition. Glasgow at least has an argument that people's own use does not fit their assumptions about 
what races are. I think I have given enough reason already to resist that claim, but to be fair to him he is not doing something as removed from actual use as what the Stoics do.

Nonetheless, he refuses to use the term most everyone uses. Even if people have false beliefs about what the term refers to, one feature is common to both the Stoic exclusion of good feelings from the category of emotions and Glasgow's refusal to call existing sociallydistinguished groups races. Both views deny reference to any actual groups, and both involve a theory about what the category must involve. The Stoics generate their theory a priori. Glasgow engages in empirical study of people's attitudes in addition to armchair intuitions about thought experiments (some still to be discussed, in section 4). But I think both theories are false or at least should acknowledge a more complex picture than their proponents allow.

One common picture of how our language latches on to entities in the world has been called the best-candidate theory, which Ted Sider pithily describes as "meaning consists of use plus eligibility." ${ }^{50}$ If this picture is correct, then our terms refer to whatever is the best candidate for reference given how we use those terms. Some candidates for reference are more eligible than others, because they fit how we use our terms better than others. There may be other criteria of some particular version of this general picture, but the main idea is that we should seek to find candidates in the world for what our terms might refer to, and we should seek to identify which candidates are better, more-eligible, candidates than others while not expecting our terms to be empty unless there are no good candidates.

If this fairly common approach is correct, as I take it to be, then we have further reason to think our race-terms successfully refer. We can come up with candidates for reference, and Glasgow has even insisted that there are very good candidates - the social kinds that he says we 
wrongly take to be races. He just thinks that they aren't races, because he thinks races have to be biological. Given that my arguments resisting that approach are correct, it fair to say that he has provided the necessary starting point for a best-candidate view, which can say that the groups he admits to existing are the best candidates for races. They are not biological, but no biological groups exist that match our use of race-terms well enough. The social groups whose existence he acknowledges, which he thinks we wrongly call races, are in fact better candidates for the reference class of our race-terms than the biological groups that he argues do not match as well with our ordinary use of race-terms. That then would give us good reason to say that races are real.

Glasgow is correct, then, to point out that many cases of social categories do not involve false beliefs about the underlying social reality, whereas with races we do have widespread false beliefs. He uses that to argue that we should think the groups might be socially-constructed entities while not accepting that they are races. But plenty of examples of socially-generated entities do involve false beliefs about the very nature of those entities, and it does not stop (a) the existence of those entities, (b) the use of the same terms for those entities by both those with the false beliefs and those who know better, or (c) correct application of the commonlymisunderstood terms to those entities. So I would conclude that the distinction between social categories with false beliefs and those without false beliefs is not enough to show that the entities we call races are not really races. If a social-kind theory of what races are allows for false beliefs that races are biological categories to be part of the mechanism that generates the existence or social significance of race, then false beliefs do not create a problem for a social-kind view. Races need not be like caloric and phlogiston but may well be more like atoms and heat, and if 
we hold to a best-candidate theory of reference then we have good reasons to think there are indeed races, even if the best candidates are groups that most people have false beliefs about.

\section{Further Thought Experiments}

Glasgow does not favor armchair theorizing, which is why he spends so much time doing experimental philosophy, but he thinks thought experiments can bolster his case. He presents several thought experiments against the idea that the categories we call races that are generated by social practices are races. This section argues that his thought experiments do not undermine social-kind races in the ways that he says they do.

He begins by distinguishing between two kinds of constructions that could constitute these groups. Probabilistic constructivism:

makes your race a function of the probabilities that you will die at a certain age, or face incarceration, or live far from environmental hazards, and so on... [It] requires that each race have its own statistical profile, detailing the various rates with which various socially malleable facts ... are true of its members. ${ }^{51}$

His Utopia counterexample envisions everyone being won over to anti-racism and reaching a point where the effects of the history of racism are no longer operable or observable in statistics. If such were to occur, would there still be races? Not the races of probabilistic constructivism. He points out, however, that commonsense understandings of race would consider the races still to be present. So we should not think of races the way probabilistic constructivism does. 
I should say that this view faces problems more immediate than his far-fetched, distant future. If two racial groups had the same statistical spread, there would be no way to individuate them. What probabilistic constructivism uses to distinguish racial groups would no longer differentiate these two groups. You might put off the inevitable by factoring in histories of the groups, but you would not want to define the races in such a way that changing social constructions would retain the same groups. If our practices and views about races changed significantly, the races would change as a result. That seems to be happening as the one-drop rule is applied much less consistently in parts of the U.S. and among certain demographics. Social categories need to be sensitive to massive changes in how social practices categorize people.

Glasgow then considers whether races could be grounded in those very categorizing practices, calling the view categorical constructivism. He proposes several counterexamples. In Disaster, a virus kills everyone over ten months old. In the last days of the dying adult population, they devise a method to keep their infants alive until they can care for themselves, and the children grow up without adult care. Glasgow then says that, according to categorical constructivism, the children suddenly have no races once the last adult dies, and they develop races only if they later begin to categorize themselves into races. Categorical constructivism has that result, but he thinks such a conclusion is counterintuitive, so it gives the wrong result.

I must confess that I have the opposite intuition. Such a situation could lead to the sudden removal of races from social reality. If you could remove all of the social practices generating the existence of races, there might no longer be races. If that is counterintuitive, it is because we still think about the case while operating under a concept of race. Perhaps I would have some hesitation, however, that races really would disappear in this case, for two reasons. One is that there might still be an entire record of history, literature, sociology, and so on. It might take the 
children a long time to figure out how to understand the languages in these books, but the record of racial categorization still exists, and perhaps the existence of races is preserved in those.

Glasgow could posit an additional disaster that maintains just enough technology to keep the children alive while losing any record of races, but there remains one fact that could still ground the existence of races. There is the history in a different sense, one that you cannot get rid of. I mean not the recorded history but the actual past of racial classification. That past is no longer present, but its occurrence might ground truths about races, even if no current social practices would on their own give rise to the existence of races. Factors like these might explain the intuition that there would still be races even in this dire circumstance. Social kinds need nonarbitrary reasons for there to be truths about races, not that any human being has access to those reasons, and in this case there are such reasons because of the past. It is hard to see Glasgow's intuition as all that decisive, then, given that others might have opposite intuitions (I do) and that we could explain his intuition based on other elements that do remain in the Disaster scenario.

Glasgow presents one final thought experiment, Temporary Amnesia. What if massive memory loss manages to affect the entire world, including (perhaps among other things) every memory related to racial classification and preventing our brains from operating correctly once we start categorizing people, thus preventing new races from being generated. Eventually the effect disappears, and racial categorization resumes. Glasgow says categorical constructivism should take races to stop existing during the time the amnesia is in effect but that the races come back into existence once the amnesia ends. But that conclusion seems counterintuitive.

In this case, I agree with his intuition, but this case has more resources to explain why that might be. As with the previous case, we still have the entire literature and historical record of racial categorization. If we wanted to eliminate that temporarily, we would have to imagine 
someone or something that could reconstruct the record once it is destroyed, and that would mean preserving a record (perhaps even just in the memories of some godlike being). But suppose the records do not return, just the memories. Would races stop existing, then, and resume their existence once the memories return? I have to agree with Glasgow that it seems strange to think the races suddenly cease their existence and then come back into existence afterward.

But the very nature of this case explains that intuition. How do the memories return? They must still be there, stored in the brains of those whose recall abilities cannot bring them to mind and whose classificatory procedures are temporarily prevented from categorizing anyone. You could not restore memories without there being some memory of them still there. Even if it were not in their brains but existed somewhere else (perhaps the way Star Trek transporters are supposed to store information during transit about the people they beam up or down or perhaps in the mind of a godlike being causing the amnesia), the construction still exists somewhere, even ignoring the existence of the past history that some might consider to ground the existence of races. There are also counterfactual truths about how those with memory loss would behave if they could remember their past racial classification, and those might be enough to ground the reality of races during the intervening period before they remember again.

So Glasgow's thought experiments rely on false assumptions about what would be sufficient to generate a racial construction. If recorded history or inaccessible memories could do so, not to mention the mere fact of the actual past, then his claim that counterintuitive conclusions follow is incorrect. Those cases are not genuine counterexamples to social-kind races. 


\section{Glasgow's summarizing argument}

At the end of it all, Glasgow leaves us with a summary argument for his anti-realism about race. He begins by restating the conclusions he draws from some of the arguments this paper has already covered:

If my judgments about these cases are on target ... then we don't want to say that whether you have a race depends on whether we can see your race, whether we happen to racially categorize you, whether you have actually had experiences based on your racial categorization, or whether there are inequalities between the races. As far as that goes, these judgments only entail that those non-biological facts are not our race-makers; they do not show that there is no social race-maker. However, when we consider that there is a gap between all of these socially constructed elements and the way race operates, and when we recall that race would seemingly vanish if our bodies all changed to look more or less the same, a generalizable pattern starts to appear: in each of the various cases meant to expose the shortcomings in constructivism, the reason that our races don't change when the relevant social facts change is that our visible traits don't change. This corroborates the suggestion that while an individual's particular race might depend on social factors, each racial group is, as a conceptual matter, defined only in terms of its purportedly distinctive visible, biological profile. And again, since these groups' putative distinctiveness is not, in point of fact, legitimated by the biology, there are no races. ${ }^{52}$

His arguments, if he is right, indicate that the social facts he is considering do not determine what the races are, because they do not determine the continued existence of races in these thought experiments. Races persist without the social facts. He postulates that this is because visible traits do not change, and this supports his conclusion that racial groups are conceptually defined only in terms of visible traits. Since there are no actual groups defined in such a way, there are no races.

I have given reasons to reject Glasgow's analysis of the particular cases. I will not grant his claim that facts about races would just vanish in some of these cases. He thinks social facts 
form an emerging pattern to show the irrelevance of those very facts, but my reasoning relies on those same facts. It's not just that there are visible traits that do not disappear. It's that there are still social facts that continue to explain the importance of those visible traits, including historical facts, possible social futures (meaning there are modal facts about counterfactual scenarios that might play a role in the continued existence of races), and recorded history that both retains the categorizations of the past and explains the continued relevance once people learn of the history. If those social facts explain our intuition that races would not be removed in such scenarios, then these thought experiments do not allow us to generalize from the existence of races in these cases to the absence of any social factors generating the existence of races. All these cases involve races disappearing once they exist, and there are too many disanalogies between such cases and possible scenarios in which race-thinking never develops to think that these cases can show much about what generates the existence of races to begin with.

Glasgow then continues his concluding argument, drawing attention to problems with criteria for membership in races:

Now add the plausible principle, from a constructivist ... : "[r]ace-thinking is about kinds, called races, and only derivatively about individuals, who thereby have racial identities... It follows that if there are no races, then no one is a member of any race, in which case we don't, for the purposes of determining whether race is real, need to go any further and sort out the myriad membership criteria by which individuals are assigned to different races (a task that, frankly, seems nearly impossible if the goal is to render those criteria consistent so that race can be real). All we need to know is that racial groups purport incorrectly to be biological. ${ }^{53}$

The assumption here is the conclusion of the first part of the argument, which I have already provided reason to resist.

But there is another argument hidden here that does not depend on that assumption. Glasgow thinks it is impossible to sort through the criteria for race-membership in a way that 
renders those criteria consistent enough to allow race to be real. He says he does not need to try to sort through that, because his first argument eliminates the possibility of real races.

Eliminating that argument does not provide an answer to the challenge that he does not think he has a need to elucidate any further. But I do not think his argument succeeds, so the undeveloped challenge then comes full force to me.

Suppose I take social processes involving racial classificatory procedures to create categories that would not exist apart from those social processes. If the classificatory conditions are inconsistent, as Glasgow thinks, then no group can fit them. This hearkens back to Appiah's claim that there cannot be groups fitting all the things we want races to $\mathrm{do}^{54}$. The argument assumes a univocal racial classificatory practice, according to which all the operating rules apply in all contexts in the same way. If our racial classifications change depending on circumstances, we might find that rules in one context are simply not at work in another context, or in some cases certain factors may become more definitive than other factors. With a sufficiently contextsensitive notion of how racial classification works ${ }^{55}$ Glasgow's more serious problem (the one he does not pursue as fully) disappears, along with Appiah's charge of inconsistency. We can explain the seemingly-inconsistent criteria in a way that does not presuppose the non-existence of groups that fit all the contradictory requirements of being the races.

These arguments for anti-realism about race, then, are unconvincing. As sections 1 and 2 argue, the ordinary concept of race is a thin concept that need not be taken to require race to be a biological category. Section 3 argues that false beliefs about the nature of race are compatible with its existence as a real category, albeit one that doesn't have the features it is thought to have by those who have those false beliefs. Section 4 resists the counterexamples Glasgow provides as 
thought experiments raised against the reality of race as a social kind. Finally, section 5 resists arguments that our race concept is too inconsistent for there to be any entities fitting the concept.

Once we distinguish between conceptions and concepts, we can find that many elements people take to be true of race that do not match up to anything in the world are part of people's conceptions of race, not necessarily part of the very concept of race. It is therefore much harder than many have taken it to be to assume that problematic features of our thinking about race must reflect problems in the very concept of race. Our very debates about race show that a wide range of views must be compatible with the concept of race in order to be meaningfully considered as genuine candidates for the meaning of the term. If we can maintain the concept while changing the conception, it favors seeing race more like heat than phlogiston, and we should see it as a genuine reality that many people have false beliefs about. Just as people can have vastly different conceptions of the nature of Halloween without thinking they are dealing with two very different holidays, we can find people with vastly different conceptions of the nature of race who nonetheless seem to be talking about the same thing.

Furthermore, it does not help the anti-realist to say that the groups people call races do exist but just are not worthy of the name 'race'. It concedes that the groups we call races do exist, even if it refuses to apply that term to them. Such a view gets our language wrong by relying on mutable and inessential beliefs about races to get to the very concept of race, which might withstand much revision on the level of conceptions. The way to figure out whether there are races is to see how we use race-language and which social groups fit mostly closely with our thin concept of race. False beliefs about those referents will not show us that the terms we use to refer to them do not refer to anything, any more than false beliefs about the referents will show us that the referents are non-existent. Finally, with enough context-sensitivity in which 
conceptions of race we apply in which situations, several contradictory conceptions of race can operate without there being one contradictory concept of race. I conclude that these anti-realist arguments do not succeed.

\footnotetext{
${ }^{1}$ Joshua Glasgow, A Theory of Race (New York: Routledge, 2009); Joshua Glasgow, Julie Shulman, and Enrique Covarrubias, "The ordinary conception of race in the United States and its relation to racial attitudes: A new approach." Journal of Cognition and Culture 9 (2009): 15-38; Julie L. Shulman and Joshua Glasgow, "Is Race Thinking Biological or Social, and Does It Matter for Racism? An Exploratory Study" Journal of Social Philosophy 41, no.3 (2010): 244-259.

${ }^{2}$ Michael Hardimon, “The Ordinary Concept of Race,” Journal of Philosophy 100 (2003): 442-447; see also Glasgow, A Theory of Race, 20.

${ }^{3}$ Robin Andreasen presents problems with forming a biological account of race based on phenotypic characteristics and geographic origin in “A New Perspective on the Race Debate," British Journal of the Philosophy of Science 49 (1998), 199-225, esp.201-206. See also Naomi Zack, Philosophy of Science and Race (New York: Routledge), pp.25-57. An anonymous reviewer has tried to convince me that Hardimon's account falls afoul of these objections. I am not sure that it does, provided that it observes the qualifications I have included in the previous paragraph. I will register that I do not think Hardimon would oppose those qualifications.

${ }^{4}$ Ian Hacking, The Social Construction of What? (Cambridge, MA: Harvard University Press, 1999), esp. pp.68-92.

${ }^{5}$ Glasgow, A Theory of Race, 20-21.

${ }^{6}$ Ibid., 21-22.

${ }^{7}$ Ibid., 84 .

${ }^{8}$ Ibid.,.86-90.

${ }^{9}$ The experimental philosophy work that has been done so far unfortunately has focused mostly on the black-white binary. Because I am mainly responding to Glasgow here, that affects my emphasis. I would prefer a data set with broader implications, but I do think this suffices for a response to Glasgow's arguments, which have the narrower focus that I have not moved much beyond.

${ }^{10}$ Sally Haslanger, "What Are We Talking About?: The Semantics and Politics of Social Kind Terms," Hypatia 20, no.4 (2005), 19-20.

${ }^{11}$ Lawrence A. Hirschfeld, Race in the Making: Cognition, Culture, and the Child's Construction of Human Kinds (Cambridge, MA: MIT Press, 1996), 166-171.

12 Ibid., 169.

${ }^{13}$ Glasgow, A Theory of Race, 63.

${ }^{14}$ Glasgow, Shulman, and Covarrubias , "The ordinary conception of race”

${ }^{15}$ Ibid., 35 .

${ }^{16}$ Mills, "But What Are You Really?: The Metaphysics of Race" in Blackness Visible: Essays on Philosophy and Race (Ithaca, NY: Cornell University Press, 1998): 41-66, esp. 61-62.
} 
${ }^{17}$ Shulman and Glasgow, "Is Race-Thinking Biological or Social”; Celeste M. Condit et al., "Attitudinal barriers to delivery of race-targeted pharmacogenomics among informed lay persons" Genetics in Medicine 5 (2003), 385-392.

${ }^{18}$ Glasgow, A Theory of Race, 69.

${ }^{19}$ Tasha N. Dubriwny, Benjamin R. Bates, and Jennifer L. Bevan, "Lay understandings of race: Cultural and genetic definitions in Community Genetics 7 (2004), 185-195.

${ }^{20}$ Nick O. Haslam, Louis Rothschild, and Donald Ernst, "Essentialist beliefs about social categories" in British Journal of Social Psychology 39 (2000), 113-127; Idem., “Are essentialist beliefs associated with prejudice?” British Journal of Social Psychology 41 (2002), 87-100.

${ }^{21}$ Glasgow, A Theory of Race, 70.

${ }^{22}$ Ibid., 70 n.8.

${ }^{23}$ Haslam et. al., "Essentialist beliefs about social categories," 117-118, Glasgow, A Theory of Race, 68 n.5.

${ }^{24}$ Debra Dickerson, “Colorblind,” Salon.com, January 22, 2007. http://www.salon.com/opinion/feature/2007/01/22/obama/.

25 Now, anyway. Italians in the U.S. weren't always considered white. See John Tehranian, "Performing Whiteness: Naturalization Litigation and the Construction of Racial Identity in America," The Yale Law Journal 109, no.4. (2000): 825827 .

${ }^{26}$ Glasgow, A Theory of Race, 70. n.9.

${ }^{27}$ Ibid., 64-66,70-71.

${ }^{28}$ Ibid., 70-71; Glasgow et. al., “The ordinary conception of race,” $20 \mathrm{ff}$.

${ }^{29}$ Glasgow, Shulman, and Covarrubias , "The ordinary conception of race," 35-36.

${ }^{30}$ Alain Locke, Race Contacts and Interracial Relations, ed. Jeffrey C. Stewart (Washington, DC: Howard University Press, 1992), esp. pp.11-13,79. See also Jacoby Adeshei Carter, "Alain LeRoy Locke” The Stanford Encyclopedia of Philosophy (Summer 2012 Edition), Edward N. Zalta (ed.), $\mathrm{URL}=<$ http://plato.stanford.edu/archives/sum2012/entries/alain-locke/>.

${ }^{31}$ Ibid., 79.

${ }^{32}$ Ron Mallon, "Passing, Traveling, and Reality: Social Construction and the Metaphysics of Race," Noûs 38:4 (December 2004), 654.

${ }^{33}$ Jorge Gracia, Surviving Race, Ethnicity, and Nationality: A Challenge for the Twenty-first Century (Lanham, MD: Rowman \& Littlefield, 2005), 85, 98.

${ }^{34}$ Paul C. Taylor, Race: A Philosophical Introduction (Malden, MA: Polity Press, 2004), 85-87.

${ }^{35}$ Lucius Outlaw, “'Conserve' Races? In Defense of W.E.B. DuBois,” in Bernard Bell, Emoly Grosholz, and James Stewart, eds., W.E.B. DuBois on Race and Culture (New York: Routledge, 1996), 21.

${ }^{36}$ Linda Martín Alcoff, Visible Identities: Race, Gender, and the Self, (New York: Oxford University Press, 2006), 91, where she says racial identity is highly non-intrinsic but often relies on characteristics like visible appearance, although in different places the characteristics are different.

${ }^{37}$ Bernard Boxill, "Introduction” in Bernard Boxill, ed., Race and Racism (New York: Oxford University Press, 2001$), 31$. 
${ }^{38}$ Ronald Sundstrom, “Race as a Human Kind,” Philosophy and Social Criticism 28 (2002), 105.

${ }^{39}$ See Glasgow, A Theory of Race, 94-102.

${ }^{40}$ To those who would say that usefulness for science is enough for a social kind to count as a natural kind, because social sciences are science, I would say that such a move would undermine the distinction between natural kinds and social kinds. The point of the distinction is to find the sorts of things that natural sciences can get to without being influenced by the kinds of thing that social science is needed to discover. Hacking's three sticking points about natural kinds are exactly the difference we find between the philosopher's notion of a natural kind and the groups we delineate in social science.

${ }^{41}$ Glasgow is responding, in the section referenced in the above note, to Robin Andreasen, "A New Perspective on the Race Debate" and Philip Kitcher, "Race, Ethnicity, Biology, Culture" in Leonard Harris, ed. Racism (Amherst, NY: Humanity, 1999), reprinted in his In Mendel's Mirror: Philosophical Reflections on Biology (2003).

${ }^{42}$ Glasgow, A Theory of Race, 118-119. An anonymous referee has argued that my argument is question-begging, because Glasgow would not grant that there are any groups that could deserve to be called races. However, I do think Glasgow grants the only premise that I need, which is that there are social groupings that we in fact call races. The only question that remains, Glasgow himself says, is whether those social groups are races. I do not think Glasgow's own claim begs the question against him.

${ }^{43}$ On one level, this now-classic example among analytic philosophers is based on a mistake, in my view. We may not want to try to be fair to those who looked for witches under every tree and superstitiously burned innocent people, but I think we shouldn't oversimplify what people believing in witches have believed. Those who call themselves Wiccans today trace their tradition to activities that many Christians have considered witchcraft, and their practices in many cases violate the biblical commandments that those Christians connect with witchcraft. So should we think of the class of witches as an empty set? I'm not sure that's fair to the intentions of those who engaged in witch hunts. There were people engaging in the activities that they took to constitute witchcraft, and thus there were people whom their standards counted as witches, whether those people were actually cavorting with Satan or not (and there are plenty of people still around today who would call such activities witchcraft). So I tend to think of this as an unhelpful example, at the very least relying on controversial assumptions. Phlogiston and caloric are better examples of clearly-empty categories that people once believed to have been non-empty, and I will focus on those instead.

${ }^{44}$ See Nicholas Smith, Fritz Alhoff, and Anand Jayprakash Vaidva, ed., Ancient Philosophy: Essential Readings with Commentary (Malden, MA: Blackwell, 2008), 47-50.

${ }^{45}$ Ibid., 307-308.

${ }^{46}$ JJ. MacIntosh and Peter Anstey, "Robert Boyle," The Stanford Encyclopedia of Philosophy (Fall 2010 edition), ed. Edward N. Zalta , http://plato.stanford.edu/archives/fall2010/entries/boyle/.

${ }^{47}$ Alan Chalmers, "Atomism from the 17th to the 20th Century", The Stanford Encyclopedia of Philosophy (Winter 2010 Edition), ed. Edward N. Zalta, http://plato.stanford.edu/archives/win2010/entries/atomism-modern/.

${ }^{48}$ Augustine, The City of God against the Pagans 9.4-5, ed. and trans. R.W. Dyson (New York: Cambridge University Press, 1998): 361-366.

${ }^{49}$ See, for example, Seneca, “On Anger” I, 7-9,12-14,17-18, in Voices of Ancient Philosophy: An Introductory Reader, ed. Julia Annas (New York: Oxford, 2001), 100-104. See also Annas’ summary of the view on p.109.

${ }^{50}$ Theodore Sider, Four-Dimensionalism: An Ontology of Persistence and Time (New York: Oxford University Press, 2001), 186.

${ }^{51}$ Glasgow, A Theory of Race, 119.

${ }^{52}$ Ibid., 123. 
${ }^{53}$ Ibid., 123.

${ }^{54}$ K. Anthony Appiah, In My Father's House: Africa in the Philosophy of Culture (New York: Oxford Univ. Press, 1992$), 45$.

${ }^{55}$ I have in mind here something like what Ron Mallon (in "Passing, Traveling and Reality," 656ff.) describes as race not traveling, which he takes from Michael Root, "How We Divide the World," Philosophy of Social Science 67 (Proceedings), 628 639, except that Mallon thinks the notion requires the person being evaluated according to race having to be in the actual context of evaluation, which does not distinguish between the context of evaluation and the context being evaluated. With Mallon's notion of race not traveling, it makes no sense to say ask whether Augustine was black by contemporary U.S. standards because of his Berber mother. The question seems meaningful, and it seems as if someone might plausibly interpret some of the U.S. racial classificational methodology, especially in the Jim Crow South, as classifying someone of what we might today call mixed race in Augustine's time as black, because those with similar ancestry who are in the Jim Crow context could be so classified, even Augustine might not be considered black or even mixed race in his own day. What I have in mind is simply that raceclassificational criteria can vary in different contexts of evaluation, not that what race you are depends on where you are. It is the different contexts of evaluation that matter for the point I am making. I just invoked three contexts of evaluation - Augustine's own time, the Jim Crow South, and my own as I write this. A social-constructionist view that allows for all three to have different truth conditions, each leading to truths within its own context of evaluation, avoids the kinds of problems Glasgow is raising (and Mallon's as well, I would argue, but that point is beyond the scope of this paper). 